\title{
IMPLEMENTAÇÃO DE AÇÕES PEDAGÓGICAS INOVADORAS NA CONSTRUÇÃO DE CONCEITOS BIOLÓGICOS NUMA PERSPECTIVA HÍBRIDA DO ENSINO: UMA REVISÃO
}

\author{
IMPLEMENTATION OF INNOVATIVE PEDAGOGICAL ACTIONS IN THE \\ CONSTRUCTION OF BIOLOGICAL CONCEPTS IN A PERPECTIVE OF HYBRID \\ EDUCATION: A REVIEW
}

\author{
Graucineide Maria de Alcântara ${ }^{1}$ \\ Islane Cristina Martins ${ }^{2}$
}

\section{RESUMO}

Introdução: Para transformar o ensino, é necessário rever e inovar as práticas de ensino, articulando saber ensinado ao saber aprendido, principalmente, no que tange aos saberes de ciências naturais, onde em sua maioria, só se trabalha o teórico, em detrimento da práxis, realidade que precisa ser transformada. Objetivo: verificar a implementação de ações pedagógicas inovadoras na construção de conceitos biológicos numa perspectiva híbrida do ensino. Materiais e Métodos: Foi feita uma busca das referências nas bases Periódicos CAPES e Google Acadêmico em março de 2021. A busca permitiu a identificação de 03 artigos que se adequaram aos critérios estabelecidos. Resultados: Foi possível verificar que, 100\% dos artigos indicam que o sistema de ensino precisa ser inovado, através de metodologias ativas, com modelos incentivadores da proatividade do discente, para que este sinta, de fato, o sentido da aprendizagem. Conclusão: Os estudos apontam que, há uma necessidade urgente de inovação do ensino, com implementação de novas metodologias, articuladas as tecnologias digitais, para que as demandas sociais possam ser atendidas, e para que o ensino passe a ter sentido na vida do aprendiz.

Palavras-chave: Ações pedagógicas; Inovadoras; Ensino híbrido; Conceitos Biológicos

\section{ABSTRACT}

Introduction: For transforming the education, it is necessary to review and innovate teaching practices, articulating knowledge taught with knowledge acquired, especially with regard to the knowledge of natural sciences, where most of them only work on the theoretical, to the detriment of praxis, reality that needs to be transformed. Objective: Verifying the implementation of innovative pedagogical actions in the construction of biological concepts in a perspective of hybrid education. Materials and methods: It was carried out a search for references in the CAPES and Google Scholar databases in March 2021. The search allowed the identification of 03 articles that met the established criteria.

\footnotetext{
I Licenciada em Ciências pela Fundação de Ensino Superior de Olinda - FUNESO, Especialista em Microbiologia Aplicada pela Universidade Federal Rural de Pernambuco - UFRPE. Professora da Secretaria Estadual de Educação de Pernambuco e da Secretaria de Educação da cidade de Recife - PE. E-mail: graucineider@hotmail.com.

${ }^{2}$ Biomédica pela Universidade Federal de Pernambuco- PE, mestre em Neurociências pelo programa de pósgraduação em Neuropsiquiatria e Ciências do Comportamento-UFPE. E-mail:islanemartins@gmail.com.
} 
Results: It was possible verifying that, I00\% of the articles indicate that the education system needs to be innovated, through active methodologies, with models that encourage students' proactivity, so that they feel, in fact, the meaning of learning. Conclusion: Studies point out that there is an urgent need for teaching innovation, with the implementation of new methodologies, articulated with digital technologies, so that social demands can be met, and so that teaching becomes meaningful in the apprentice's life.

Keywords: Pedagogical actions; Innovative; Hybrid education; Biological Concepts;

\section{INTRODUÇÃO}

O conhecimento construído é considerado significativo quando, de alguma forma faz sentido para a vida do sujeito, contribuindo assim, com a sociedade na qual o mesmo faz parte (Moraes, 2016; apud. Bock et al. 2008).

Nesse sentido, as ações pedagógicas inovadoras são estratégias usadas no processo de ensino, facilitando a compreensão dos conteúdos pelo discente (Moraes,2016).

Nessa perspectiva, para que um processo seja implementado, faz-se necessário a exposição do sujeito a essa nova situação, onde o mesmo poderá construir e enriquecer sua bagagem com significativos conhecimentos (Müller; Araujo; Veit, 2018).

Assim sendo, as estratégias inovadoras de ensino surgem como peças facilitadoras, para que os sujeitos construam e compreendam com mais clareza os conceitos científicos (Moraes, 2016).

Nessa esteira, o uso de ações pedagógicas inovadoras tem por finalidade aprimorar o aprendizado do sujeito, ofertando-lhe meios criativos, interativos e motivadores, para construir seu conhecimento (Moraes, 2016).

Nesse viés, entende-se que as metodologias ativas incentivam a proatividade do sujeito no processo de construção e inovação do próprio conhecimento, podendo, assim, desenvolver habilidades e competências essenciais no processo de aprendizagem (Costa; Oliveira; Dantas, 2020).

Nesse sentido, o Ensino Híbrido é um programa que mistura aula presencial e online, articulando sujeito e tecnologia, porém, focando na aprendizagem personalizada do discente (Christensen; Horn; Staker, 2013).

Assim sendo, o modelo de Rotação por Estações, Laboratório Rotacional e Sala de Aula Invertida compreendem o modelo sustentado de ensino, enquanto que, o modelo Flex, A La Carte e o Virtual Enriquecido compreendem a forma disruptiva (Christensen; Horn; Staker, 2013).

Nesse contexto, os modelos híbridos que seguem o caminho sustentado, tendem a se construir associando-se ao modelo tradicional de ensino, possibilitando assim, melhorias neste modelo antigo (Christensen; Horn; Staker, 2013).

Porém, os modelos disruptivos propõem modificar o sistema tradicional de ensino, tornando-se peça fundamental deste desafio, onde o tempo, para sua consolidação, não é um obstáculo ((Christensen; Horn; Staker, 2013). 
Nesse contexto, a articulação entre as estratégias desenvolvidas é um dos aspectos do ensino híbrido, onde os estudos online e presencial se conectam, através dos conteúdos trabalhados, integrando assim, os conhecimentos ((Christensen; Horn; Staker, 2013).

Nessa premissa, o modelo de Rotação, o modelo Flex, o A La Carte e o modelo Virtual enriquecido são os modelos mais relevantes, atualmente, no mercado (Christensen; Horn; Staker, 2013).

Sendo assim, no modelo de Rotação os alunos passam por estações que apresentam atividades diferentes, e sob orientação dos professores, onde em cada estação há interação com uso com atividade online (Christensen; Horn; Staker, 2013).

Nessa premissa, no modelo Flex os alunos seguem um roteiro de atividades personalizadas, onde o ensino online é de suma importância, porém, o ensino offline não esteja descartado, e o docente se faça presente (Christensen; Horn; Staker, 2013).

Nesse viés, no modelo A La Carte, os alunos tem participação totalmente online, e sob orientação docente, porém, podem continuar frequentando as escolas tradicionais, até mesmo para o uso das ferramentas tecnológicas, no ensino online (Christensen; Horn; Staker, 2013).

Contudo, no modelo Virtual Enriquecido, o aluno se divide entre o tempo integral na unidade física e o ensino remoto online acessando as atividades a serem feitas (Christensen; Horn; Staker, 2013).

Nesse contexto, compreender os conceitos biológicos, é de suma importância, para que os indivíduos entendam o mundo ao seu redor, e possam tomar decisões individuais ou coletivas (Lima, 2009).

Porém, para que haja compreensão dos conceitos biológicos, várias metodologias devem ser implementadas, tornando assim, o processo de ensino e aprendizagem significativo para o sujeito (Lima, 2009).

Nessa premissa, percebe-se que o insistir no modelo tradicional de ensino onde o sujeito é um mero espectador, não faz mais sentido, tendo em vista, que as demandas sociais são outra, e mais exigentes. Contudo, para transforma o ensino, é necessário rever e inovar as práticas de ensino, articulando saber ensinado ao saber aprendido, principalmente, no que tange aos saberes de ciências naturais, onde em sua maioria, só se trabalha o teórico, em detrimento da práxis, realidade que precisa ser transformada.

Por isso, o objetivo do presente estudo foi realizar uma revisão integrativa da literatura a fim de verificar a implementação de ações pedagógicas inovadoras na construção de conceitos biológicos numa perspectiva híbrida do ensino.

\section{MATERIAIS E MÉTODOS}

Foi feito um levantamento da literatura em março de 202I, nas bases de dados Periódicos CAPES e Google Acadêmico. Os descritores utilizados foram os seguintes: "Ações pedagógicas" AND "Inovadoras" AND "Ensino híbrido" AND "Conceitos biológicos" AND "Pedagogical actions" AND "Innovative" AND "Hybrid teaching" AND

"Biological concepts" em todas as bases de dados. Foram selecionados 03 artigos sendo 
incluídos segundo os critérios de elegibilidade conforme a Figura I. Os critérios de inclusão foram: artigos nos idiomas inglês e português, nos últimos cinco anos, envolvendo ações pedagógicas inovadoras na construção de conceitos biológicos numa perspectiva híbrida do ensino. Os critérios de exclusão foram artigos de revisão de literatura.

FIGURAı.FLUXOGRAMA E CRITÉRIOS DE SELEÇÃO E INCLUSÃO DOS ARTIGOS.
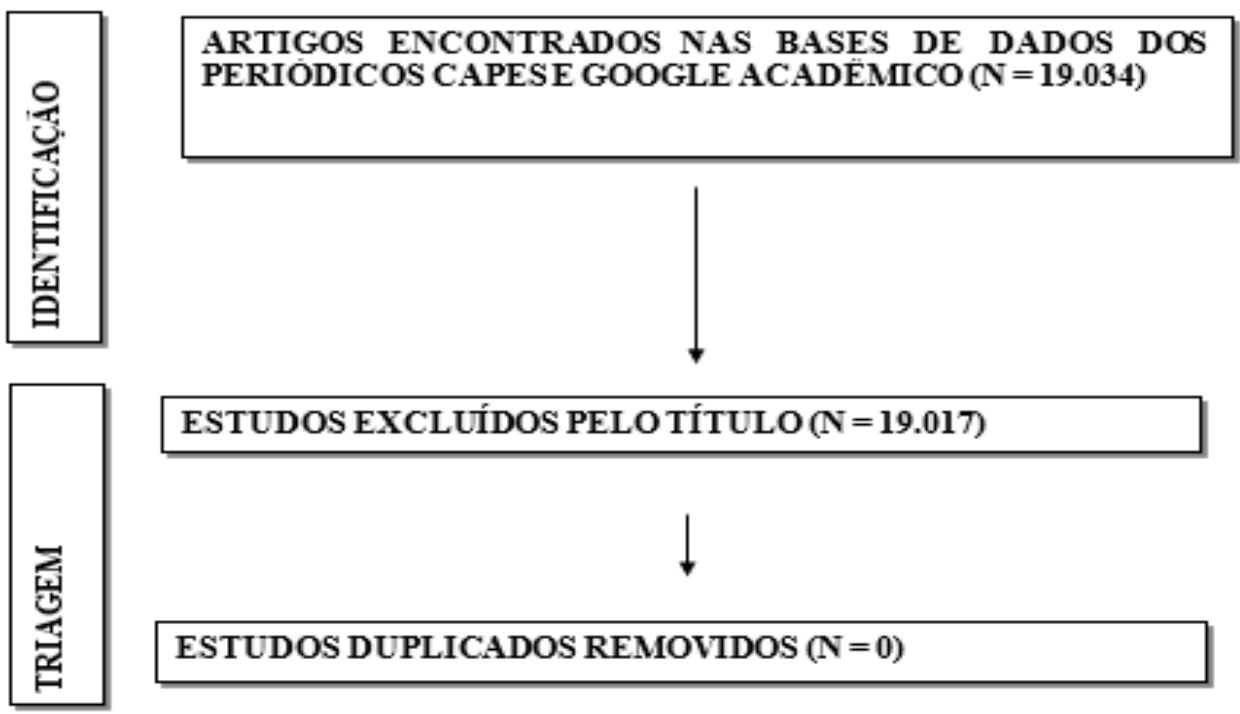

ESTUDOS EXCLUIDOS PELO TÍTULO $(\mathrm{N}=19.017)$
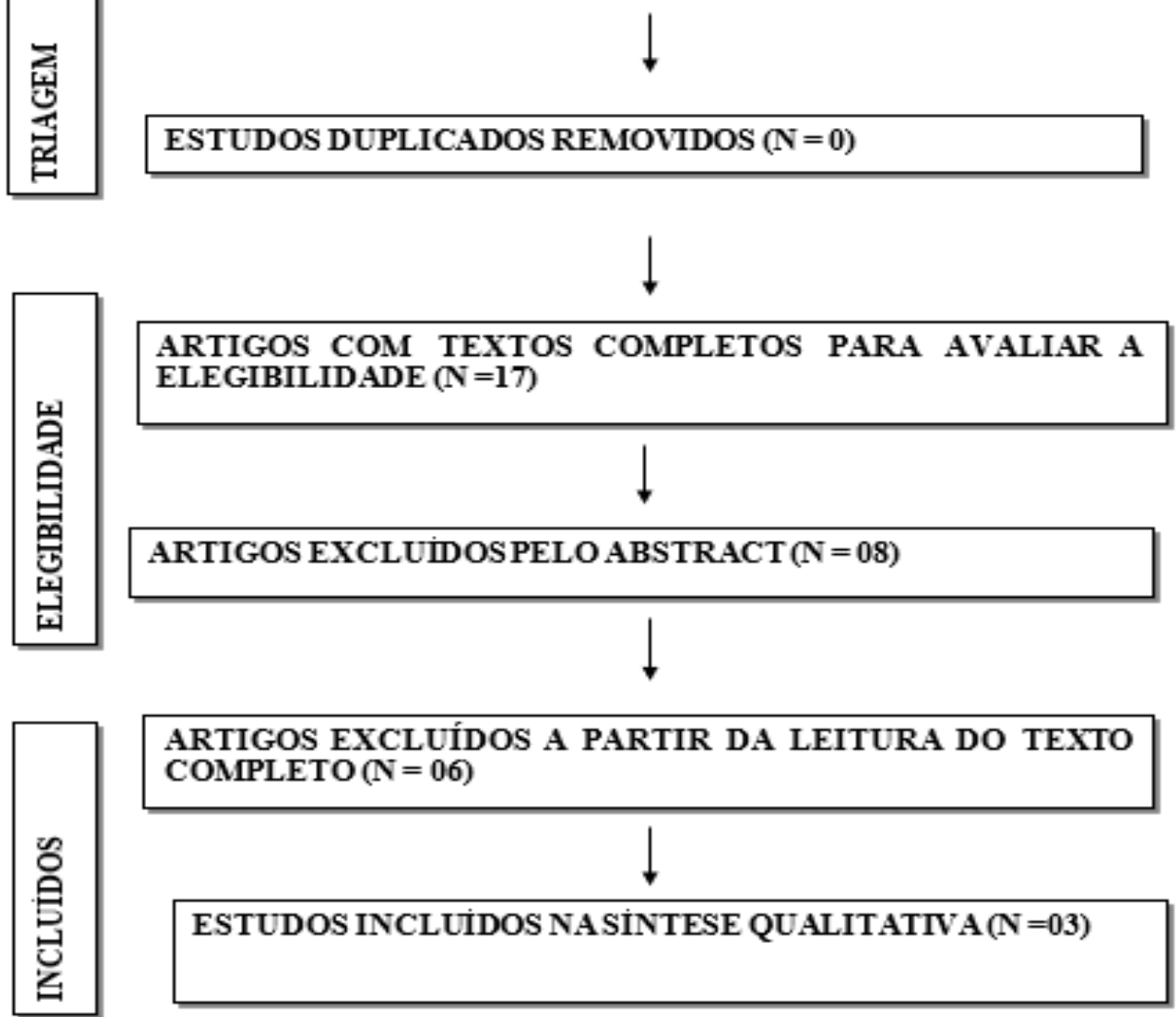

\section{RESULTADOS}

Os resultados do presente estudo encontram-se na Tabela I. 
Tabela I - Demonstrativo dos artigos que integram a revisão integrativa.

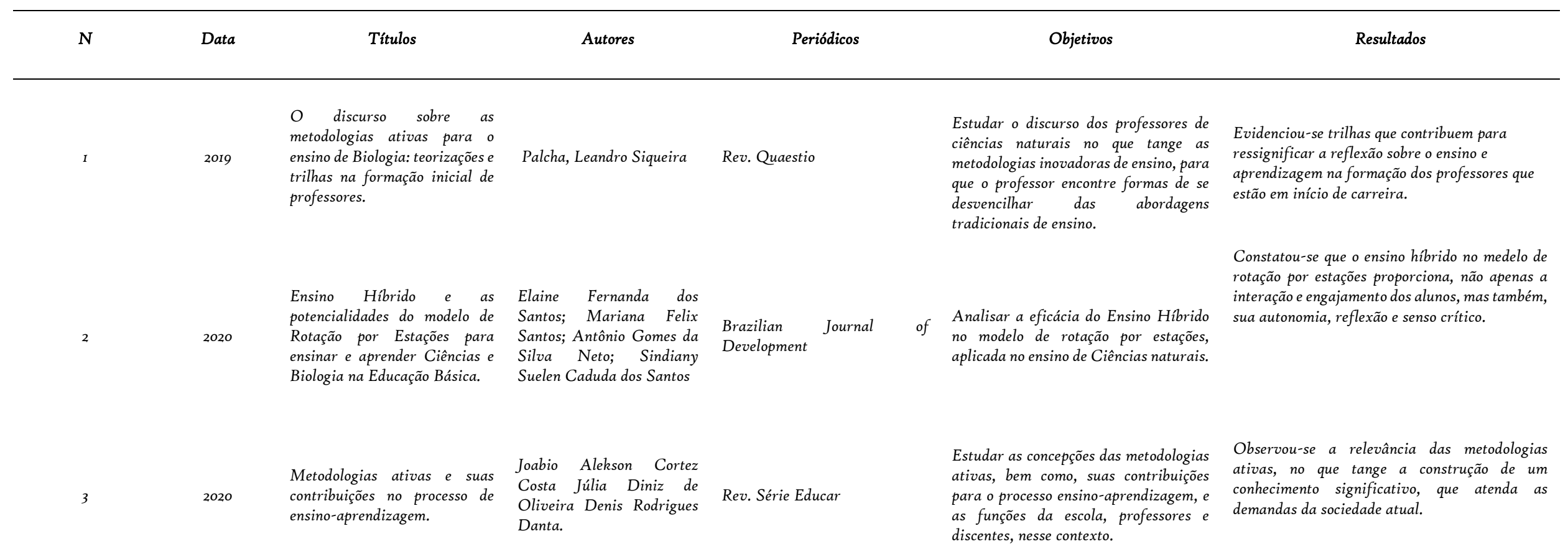




\section{DISCUSSÃO}

O objetivo do presente estudo foi investigar, a implementação de ações pedagógicas inovadoras na construção de conceitos biológicos, numa perspectiva de ensino híbrido.

Nesse sentido, o ensino baseado em metodologias tradicionais, que coloca o docente em evidência, suprimindo a atuação do aluno, que é o sujeito principal do processo, não atende mais as demandas da sociedade atual (Costa; Oliveira; Dantas, 2020).

Isso porque, atualmente, as pessoas tem acesso ao saber com mais facilidade, e isso se deve aos avanços tecnológicos, através dos quais pode se obter inúmeras informações armazenadas em bancos de dados ( Costa; Oliveira; Dantas, 2020).

Nesse viés, faz-se necessário repensar as funções da nova escola, e os procedimentos pedagógicos ofertados aos estudantes na construção de seus conhecimentos (Costa; Oliveira; Dantas, 2020).

Nesse sentido, para a sociedade de hoje, há uma expectativa de que os alunos sejam protagonistas no processo de ensino-aprendizagem, construindo com seus pares, em diferentes situações e contextos (Costa; Oliveira; Dantas, 2020).

Isso porque, no ensino tradicional, onde a metodologia é centrada na transmissão de conhecimentos, o aluno é apenas um sujeito passivo, mero receptor de informações (Costa; Oliveira; Dantas, 2020).

Nessa esteira, percebe-se a necessidade de uma transformação nos modos de ensinar, e nas ações pedagógicas, para que o objeto e o sujeito do conhecimento se encontrem num processo significativo e interativo de ensino (Costa; Oliveira; Dantas, 2020, Apud. Daros, 2018).

Sendo assim, as metodologias ativas são apontadas como aquelas que estigam a participação efetiva do aluno na construção de saberes, onde se exige a construção de novas habilidades e competências que contribuam para uma aprendizagem mais significativa (Costa; Oliveira; Dantas, 2020).

Nesse viés, um dos aspectos importantes das metodologias ativas é o respeito ao tempo, habilidades, competência e conhecimentos prévios do aluno, indicadores relevantes na construção de novos saberes (Costa; Oliveira; Dantas, 2020).

Isso se deve ao fato de que, as metodologias ativas despertam no aluno, não só o engajamento, mas também, sua independência para construir uma aprendizagem significativa (Costa; Oliveira; Dantas, 2020, apud. Berbel, 2011).

Porém, para que as metodologias ativas sejam inseridas nas escolas, é preciso um trabalho reflexivo de todos os envolvidos no contexto, no que tange aos métodos de ensino, função da escola, conceitos e perspectiva da educação (Costa; Oliveira; Dantas, 2020). 


\section{oPen 2 access}

Nesse contexto, o professor deixa de ser protagonista, para ser um facilitador, mediador da aprendizagem, conduzindo seus alunos, de maneira individual ou coletiva, para que construam seu próprio conhecimento (Costa; Oliveira; Dantas, 2020)

Assim sendo, a escola deverá ser preparada para a nova realidade, pois, metodologias inovadoras necessitam de espaços e estruturas compatíveis, para que novas ações possam ser desenvolvidas (Costa; Oliveira; Dantas, 2020).

Nesse viés, o Ensino Híbrido se mostra como uma ótima ferramenta de ensino, apresentando metodologias ativas, dinâmicas, onde se articula conhecimento e tecnologia, intercalando o ensino na forma online e a forma presencial supervisionada (Lima, 2009).

Assim sendo, entende-se como ensino híbrido, um programa que mescla a forma online e presencial de ensino e aprendizagem, sendo esta última, realizada em um espaço físico fora da residência do aluno (Christensen; Horn; Staker, 2013).

Nesse contexto, o ensino híbrido apresenta quatro modelos principais: modelo de rotação, modelo flex, modelo à la carte e modelo virtual enriquecido, compondo este programa (Christensen; Horn; Staker, 2013).

Contudo, faz-se necessário refletir sobre a possibilidade de práticas inovadoras com o uso das tecnologias digitais da informação e comunicação, a fim de transformar os métodos tradicionais de ensino (Müller; Araujo; Veit, 2018).

De fato, de alguma forma, as tecnologias digitais de informação e comunicação (TDICs) estão inseridas nas escolas. Assim sendo, uma metodologia apoiada apenas no uso do livro didático não basta. Novos recursos precisam ser inseridos, na construção de conceitos em Biologia (Santos et al.,2020).

Nesse viés, com os recursos das TDICs, os alunos podem ter acesso a uma imensidão de informações de ciências e biologia, por exemplo, em qualquer espaço e a qualquer hora, enfatizando que o método tradicional de ensino tende a perder espaço no contexto atual de ensino (Santos et al.,2020).

Nesse contexto, várias plataformas estão sendo criadas, para que os alunos tenham acesso à conteúdos de várias ciências, inclusive as ciências naturais. Como exemplo de plataformas educativas destacamos: Khan Academy, Mangahigh, Geekie e YouTubeEdu (Santos et al., 2020).

Porém, trabalhar o ensino híbrido de forma sustentada é uma boa forma de inserir este programa na escola pública, uma vez que, o ensino tradicional ainda está muito enraizado. Assim sendo, inicialmente, pode se inserir o ensino online ao modelo tradicional (Santos et al., 2020).

Contudo, faz-se necessário a articulação entre ensino e discurso das ciências, a fim de formar alunos críticos e atuantes nas tomadas de decisões dentro e fora do contexto escolar (Palcha, 2020). 
Porém, aprender e ensinar ciências se faz com questionamentos, problematizações e levantamentos de hipóteses, sobre o contexto social em que se está inserido, buscando resposta para que as dúvidas não se consolidem na construção do conhecimento discente (Palcha, 2020).

Nessa esteira, articular a formação inicial de docentes às escolas de ensino básico, futuro campo de trabalho destes, faz-se necessário, para conectar as inovações pedagógicas às metodologias conservadoras das escolas ( $\mathrm{Palcha}, 2020$ ).

Sendo assim, cabe as instituições de ensino superior ofertar aos graduandos do ensino de ciências naturais, uma visão crítica e reflexiva do ensino inovador, o qual vem contribuindo com a transformação da educação (Palcha, 2020).

Considerando o exposto, o ensino de ciências vem sofrendo transformações, a fim de aprimorar a formação dos discentes, e para atender as demandas da sociedade (Moraes, 2016 apud. Santos, 2006).

Isso porque, análises sobre o ensino de ciências apontam para métodos tradicionais que separam teoria e prática, resquícios das metodologias adotadas nas aulas, onde o professor, na maioria das vezes, tem poucos recursos, como o livro didático, por exemplo (Moraes, 2016).

Porém, para que o ensino de ciências atenda as expectativas sociais, as metodologias usadas precisam articular os conteúdos as necessidades dos discentes, contribuindo assim, com a sua formação (Moraes, 2016).

Todavia, percebe-se um largo distanciamento entre o ensino de ciências e a vida real do estudante, levando a não percepção, pela sociedade, da articulação existente entre o conteúdo ensinado e o dia a dia dos sujeitos inseridos nesta (Moraes, 2016).

Nesse sentido, verifica-se a urgência em ofertar aos alunos a oportunidade de construir um conhecimento significativo, que faça diferença em sua vida, e na sociedade como um todo, assim sendo, seu engajamento no processo será mais prazeroso e produtivo (Moraes, 2016).

\section{CONCLUSÃO}

O objetivo do presente estudo foi investigar, a implementação de ações pedagógicas inovadoras na construção de conceitos biológicos, numa perspectiva de ensino híbrido.

Nesse sentido, faz-se necessário uma inovação do ensino do ensino atual que, vem se mostrando bastante ineficaz, para atender as demandas sociais deste século, pois, o pensamento e as necessidades das pessoas, hoje, são diferentes daquelas do passado.

Nesse viés, percebe-se que novas metodologias precisam ser inseridas no processo de ensino e aprendizagem, para que o sujeito possa construir seu conhecimento percebendo o sentido e a importância deste para a sociedade.

Nessa esteira, as tecnologias tem sido uma grande aliada no processo transformador educacional, pois, as metodologias ativas se articulam bastante com as 
tecnologias digitais de informação e comunicação (TDICs), as quais vem auxiliando bastante na construção de uma nova forma de ensinar e aprender.

Assim sendo, o ensino híbrido tem sido um programa que apresenta metodologias interessantes que usa a tecnologia para unir ensino e aprendizagem de forma inovadora, onde o aprendiz pode construir com autonomia seu próprio conhecimento.

Enfim, as transformações são necessárias, e acontecem ao longo do tempo, e na educação não pode ser diferente, e todos, que dela fazem parte, precisam buscar essa transformação, para se adequar as novas formas de ensinar e aprender.

\section{REFERÊNCIAS}

CHRISTENSEN, C. M.; HORN, M. B.; STAKER, H. Ensino Híbrido: uma Inovação Disruptiva? Disponível em: 〈www.christenseninstitute.org/publications/ensino-hibrido/〉. Acesso em: 30 mar. 2021.

COSTA, Joabio Alekson Cortez; OLIVEIRA, Júlia Diniz de; DANTAS, Denis Rodrigues. Metodologias Ativas e Suas Contribuições no Processo de Ensino-aprendizagem. Série Educar

- Volume 40 - Prática Docente. Belo Horizonte, editora Poison, n.I, p.8-I4, 202o. DOI: $10.36229 / 978-65-86127-71-3 . C A P .01$

LIMA, Luciana de. Ensino de Conceitos Biológicos: a Relação entre Aprendizagem Significativa e Objetos Educacionais Digitais. Instituto UFC virtual - Universidade Federal do Ceará, Fortaleza. Disponível em: <www.brie.org/pub/index.php/sbie/article/view/II34>. Acesso em: 29 mar. 2021.

MORAES, Tatyane da Silva. (2016). Estratégias inovadoras no uso de recursos didáticos para o ensino de ciências e biologia. Dissertação (Mestrado Profissional Gestão e Tecnologias Aplicadas à Educação) - Universidade do Estado da Bahia, Salvador.

MÜLLER, Maykon Gonçalves; ARAUJO, Ives Solano; VEIT, Eliane Angela. A. Inovação na prática docente: um estudo de caso sobre a adoção de métodos ativos no ensino de Física universitária. Revista Electrónica de Enseñanza de las Ciencias v. I7, n.I, p. 44-67, 2018.

PALCHA, Leandro Siqueira. O discurso sobre as metodologias ativas para o ensino de biologia. Quaestio - Revista de Estudos em Educação, v. 22, n. 3, p. 917-938, 23 dez. 2020. 
SANTOS, Elaine Fernanda dos; SANTOS, Mariana Felix; NETO, Antônio Gomes da Silva; SANTOS, Sindiany Suelen Caduda dos. Ensino Híbrido e as potencialidades do modelo de rotação por estações para ensinar e aprender ciências e biologia na e básica. Brazilian Journal of Development, v. 6, n. 10, p. 76129-76147, 2020. 